\title{
Contexto, territorialidad y trayectorias escolares. Estudio de caso de jóvenes provenientes de familias migrantes bolivianas hortícolas del periurbano platense.
}

\author{
Context, territoriality and school trajectories. Case study of young people from \\ Bolivian horticultural migrant families from the peri-urban area of La Plata
}

\author{
Melina Morzilli \\ melinamorzilli@gmail.com \\ Instituto de Investigaciones en Humanidades y \\ Ciencias Sociales (UNLP -CONICET). Facultad de \\ Humanidades y Ciencias de la Educación. \\ Universidad Nacional de La Plata, Argentina
}

Recepción: 10 Febrero 2021

Aprobación: 11 Mayo 2021

Publicación: 01 Julio 2021

Cita sugerida: Morzilli, M. (2021). Contexto, territorialidad y trayectorias escolares. Estudio de caso de jóvenes provenientes de familias migrantes bolivianas hortícolas del periurbano platense.. Trabajos y Comunicaciones, (54), e148. https://doi.org/10.24215/23468971e148
Resumen: Este trabajo tiene como objetivo dar cuenta de la incidencia del contexto histórico y la territorialidad en las trayectorias escolares de jóvenes de familias migrantes bolivianas dedicadas a la horticultura, que se encuentran en situaciones de vulnerabilidad social. Para ello, se describen las características del contexto histórico y la territorialidad en que habitan los/as jóvenes seleccionados/as, como también, se analizan sus trayectorias escolares y los sentidos que le otorgan a la escolaridad. Se realiza un estudio de casos situado en el periurbano hortícola platense durante una cohorte de 2011-2017, en una Escuela Media Pública en la que un porcentaje relevante (casi la mitad de la matrícula) de sus alumnas/os, son migrantes bolivianas/os o hijas/os de migrantes bolivianos/as. La metodología implementada es de carácter cualitativo y, se utilizan como técnicas de recolección/coconstrucción de datos, fuentes primarias, encuestas, entrevistas en profundidad y observación participante, y se recurre a los archivos de la Escuela. Por último, se destaca que el contexto histórico y la territorialidad son dimensiones que inciden en las trayectorias escolares.

Palabras clave: Contexto, Territorialidad, Trayectorias escolares, Jóvenes, Migrantes bolivianos hortícolas.

Abstract: This work aims to account for the incidence of the historical context and territoriality in the school careers of young people from Bolivian migrant families dedicated to horticulture, who are in situations of social vulnerability. For this, the characteristics of the historical context and the territoriality in which the selected young people live are described, as well as their school careers and the meanings they give to schooling are analyzed. A case study located in the peri-urban horticultural region of La Plata is carried out during a cohort from 2011-2017, in a Public Middle School in which a relevant percentage (almost half of the enrollment) of its students are Bolivian migrants. or children of Bolivian migrants. The methodology implemented is qualitative in nature and primary sources, surveys, in-depth interviews and participant observation are used as data collection / co-construction techniques, and the archives of the School are used. Finally, it is highlighted that the 
historical context and territoriality are dimensions that affect school careers.

Keywords: Context, Territoriality, School paths, Young boys, Bolivian horticultural migrants.

\section{INTRODUCCIÓN}

Este trabajo tiene como objetivo dar cuenta de la incidencia del contexto histórico y la territorialidad en las trayectorias escolares de jóvenes de hogares migrantes bolivianos/as dedicados a la horticultura, que se encuentran en situaciones de vulnerabilidad social ${ }^{1}$.

En lo que respecta a las trayectorias escolares en el nivel medio, se debe tomar en cuenta que en la primera parte del siglo XXI se dio la masificación del ingreso a dicho nivel y la obligatoriedad del mismo. A pesar de este proceso, existen estudios que indicaron que las mejoras en la matriculación del nivel educativo medio no tuvieron en paralelo mejoras en las tasas de egreso. En este sentido, Bottinelli (2017) sostuvo que existen dificultades para avanzar en la escolarización de un $10 \%$ de jóvenes que aún no asisten a dicho nivel e incluso los valores de graduación no superan los dos tercios de jóvenes mayores de veinte años.

El hecho de que la Escuela elegida ${ }^{2}$ sea media y pública se debió, a que sumado a lo anteriormente señalado, América Latina en la actualidad se enfrenta a desafíos diferentes si se mira las metas en educación primaria o en educación secundaria. En otras palabras, los objetivos se orientan a la universalización del nivel medio.

Ahora bien, por otro lado, en cuanto al espacio territorial periurbano hortícola platense, el mismo forma parte de la Provincia de Buenos Aires, y a su vez, pertenece al cordón hortícola del sur del Gran Buenos Aires. Durante los últimos años se convirtió en el cordón hortícola más importante del país, desplazando del mercado a otros cordones verdes (García \& Le Gall, 2010; García, 2011; Lemmi, 2014). Este cordón desde la década del 70' comenzó a poblarse de migrantes principalmente provenientes de Bolivia para dedicarse en su mayoría a la horticultura (Hang et al: 2007; Benencia, 1999; 2006; Benencia et al, 2005; 2009; 2016; Barsky, 2005; Attademo, 2005; García, 2011). Estos hogares se encuentran en situación de vulnerabilidad social. Los/as jóvenes de estas familias junto a sus padres y madres son quienes alimentan a gran parte del país y, paradójicamente se encuentran viviendo en situaciones de vulnerabilidad social.

Una de las características de las trayectorias escolares de jóvenes de familias migrantes bolivianas dedicadas a la horticultura es que están acompañadas de trayectorias socio-productivas. Es necesario destacar, que estos/ as jóvenes son miembros de hogares que se dedican a la agricultura familiar (Cieza, 2012). Es decir, hogares en donde todos sus miembros trabajan en tareas productivas. En estos casos los/as jóvenes realizan grandes esfuerzos por transitar la Escuela al mismo tiempo que trabajan con sus familias en las quintas.

Por lo tanto, el análisis sobre la incidencia del contexto histórico y la territorialidad en las trayectorias escolares de las jóvenes generaciones sería fundamental, en tanto que siguiendo a Bourdieu (1998) el contexto histórico y la territorialidad son elementos estructurales que conforman la matriz de relaciones objetivas en la cual éstos/as jóvenes transitan y a su vez, construyen sus trayectorias. Analizar esto sería fundamental para generar un conocimiento más amplio y producir herramientas que contribuyan a políticas públicas orientadas a la inclusión socio-educativa de migrantes latinoamericanos.

El período seleccionado se circunscribió a los años 2011-2017. Este período posibilitó analizar trayectorias que se encontraban en diversos tramos del nivel, ya que, algunos/as jóvenes se encontraban cursando los primeros años, otros/as estaban en los años del medio, mientras que otros/as estaban cursando los últimos años del secundario.

Sumado a todo lo descripto, en los casos de inmigrantes del Estado plurinacional de Bolivia, la alteridad implica una subordinación que, bajo distintas formas, ha dificultado las trayectorias escolares exitosas (Novaro, 2011). En este sentido, como ya se ha señalado, con el objetivo de contribuir a los estudios sobre 
inclusión socio-educativa de migrantes latinoamericanos, desde la historia oral y a partir de una metodología cualitativa, es que nos preguntamos cómo inciden el contexto histórico y la territorialidad en las trayectorias escolares de jóvenes de familias migrantes hortícolas del periurbano platense que se encuentran subordinados por su alteridad, que viven en situación de vulnerabilidad social y a su vez estudian y trabajan al mismo tiempo.

En adelante, se señalan los antecedentes y el marco teórico; luego se expone la metodología y las fuentes; posteriormente, se describe el contexto histórico y la territorialidad en donde habitan y transitan los/as jóvenes seleccionados/as; a continuación se presentan las trayectorias escolares de dichos/as jóvenes y los sentidos que le otorgan a la educación y por último, se realizan las reflexiones finales observando la incidencia del contexto histórico y la territorialidad en las respectivas trayectorias.

\section{ANTECEDENTES Y MARCO TEÓRICO}

Este trabajo se articula en torno a dos ejes conceptuales. Dichos ejes se eligieron, puesto que, responden a investigaciones cuyos aportes este trabajo pretende retomar, y luego contribuir a los mismos. En este sentido, el primer eje está constituido por investigaciones sobre el periurbano hortícola platense. Mientras que el segundo eje, se vincula específicamente con la escolaridad en el nivel medio de los/as migrantes bolivianos/ as en Argentina ${ }^{3}$.

Entonces, con respecto al primer eje, se ha encontrado un estudio del cordón hortícola platense (Hang, et al; 2007) en el que predominaron cuestiones técnico-productivas que tuvieron por objeto producir conocimiento y comunicar información económica y tecnológica sobre los diferentes aspectos que hacen al proceso de producción y comercialización de hortalizas. En esta investigación también se realizaron entrevistas a los productores, ingenieros agrónomos, y a todos aquellos vinculados al sector hortícola. En dichas entrevistas prevaleció el horticultor "criollo" (argentino) o "gringo" (descendiente de inmigrantes ultramarinos). Empero, en las últimas entrevistas aparecieron los productores migrantes de países vecinos. Hang et al concluyó en sus estudios que, se debe atender más a las necesidades de un mayor colectivo de actores, reconociendo su heterogeneidad y la necesidad de tener presente esta característica al momento de su formulación. Por su parte, García (2011), ha investigado temas sociológico-productivos utilizando las herramientas teóricas de Pierre Bourdieu, haciendo especial hincapié en los productores de origen boliviano del periurbano hortícola platense. Abordó el análisis de la acumulación del capital y ascenso social del horticultor boliviano, y su rol en las transformaciones de la estructura agraria hortícola platense en los últimos 20 años.

Por otro lado, varias investigaciones (Ringuelet, Cacivio \& Simonatto, 2006; Archenti, 2008; Attademo, Ringuelet, \& Salva, 2005; Attademo, 2009) estudiaron las transformaciones campesinas del periurbano hortícola platense, sus migraciones. Concluyeron que existen componentes regionales con heterogeneidades que deben ser explicadas. Estas investigaciones, definieron las diferentes características que conformaron a los sujetos de la horticultura platense en los últimos 30 años. Partieron de la condición étnico-nacional de los sujetos e hicieron énfasis en las diferentes estrategias productivas, las lógicas de reproducción familiar, condiciones de vida, formas de tenencia de la tierra y condiciones pobreza. Fueron pioneras en la descripción e intento de conceptualización de la relación de mediería. En la segunda etapa de investigación utilizaron herramientas teóricas bourdieanas, realizando un giro hacia la cultura y una mirada al agente.

Por su parte Attademo, Waisman \& Rispoli (2011) han dado cuenta de que la categoría familiar ha sido una constante en la actividad hortícola platense más aún cuando se han producido importantes recambios en la estructura social en los últimos veinte años y la organización de esta producción no se ha alterado, siendo mayoritariamente familiar. Sostuvieron que la clave de esta cuestión radica en la relevancia funcional de la organización familiar de la actividad económica. Al ser simultáneamente una unidad de producción y reproducción, estaría dispuesta a soportar las irregularidades en los niveles de acumulación y la impredecibilidad del lucro, derivadas de una actividad sumamente inestable que afronta una amplia 
variabilidad de riesgos. La funcionalidad de la producción familiar en el contexto capitalista es que acepta -y ha aceptado históricamente-, tasas de retorno inferiores a las que concebiría como aceptables una horticultura empresarial.

A su vez, están las investigaciones historiográficas sobre las clases sociales en la horticultura platense (Lemmi, 2011; 2014) en donde se propone historizar el largo plazo la realidad hortícola platense con deseos de ascenso social, y concluye que los/as productores poseen la característica de ser inmigrantes que en sus anhelos de ascenso social llegaron a La Plata para comenzar a trabajar en su forma de peón y peón mediero.

Por otra parte, Garatte (2015) abordó las trayectorias de jóvenes productores arrendatarios de la horticultura del periurbano de La Plata en la post convertibilidad (2003-2015). En su estudio concluyó que existe una ruptura que los jóvenes efectúan respecto de los universos simbólicos familiares y las diferentes formas de auto-percibirse que tienen entre sí, tanto respecto de los sistemas de representaciones que las familias tienen respecto de la educación, como así también respecto del trabajo en la horticultura, a su vez, sostuvo que los/as jóvenes o bien no culminan sus estudios en el nivel medio, y aquellos/as que si lo hacen no siguen estudios superiores y se quedan en la quinta.

Por otro lado, se encuentran las investigaciones que analizaron temáticas que involucran la dimensión educación y migrantes bolivianos/as, éstas han sido recientes y relativamente pocas. Estos estudios observaron desde los parámetros de identificación (a pesar del cambio en las retóricas) que los discursos continúan siendo fuertemente eurocéntricos y, se construyen y sostienen imágenes que oponen la valoración de la migración europea a la representación de la migración latinoamericana como incivilizada. Sostuvieron que la escuela es la institución donde se van consolidando estas imágenes, junto con una forma del nacionalismo que al tiempo que integra y afirma igualar, excluye y discrimina. Finalmente, sus conclusiones fueron que, a pesar de la presencia masiva y la mayor igualdad en el plano legal, el registro etnográfico en las escuelas da cuenta de que no se han revertido muchas situaciones de desigualdad, y junto con nuevas retóricas coexisten viejas y nuevas formas de exclusión educativa y situaciones que ponen límites al acceso a derechos en condiciones de igualdad para los/as migrantes bolivianos/as, haciendo un muchos casos que sus trayectorias escolares en el nivel medio se vean interrumpidas (Domenech, 2005; Nobile, 2016; Salva \& Lago, 2012; Diez, 2014; Gavazzo, Beheran \& Novaro, 2014 \& Novaro, 2016).

Por su parte, Binstock \& Cerruti (2012), realizaron una contribución al conocimiento de las relaciones entre educación y migrantes incorporando al análisis otras dimensiones: la especificidad migratoria del fenómeno y la mirada de los propios protagonistas (los/as adolescentes inmigrantes en general, entre ellos/ as los/as bolivianos/as), teniendo en cuenta, además, el grupo y generación migratoria de pertenencia. Concluyeron que existe un mejor rendimiento entre los estudiantes de primera y segunda generación, particularmente los/as de origen boliviano/as. A su vez, observaron una mejor disciplina de los/as alumnos/as extranjeros/as y un estricto control ejercido por los padres sobre sus hijos/as, en particular los padres oriundos de Bolivia. Los/s adolescentes extranjeros/s declararon con mucha mayor frecuencia que los/as nativos/as el haberse sentido discriminados/as. En cuanto a la participación en el mercado de trabajo concluyeron que el mismo trae consecuencias negativas que provocan en el rendimiento de los/as jóvenes.

Otro aporte al campo de estudio en cuestión fue el realizado por Beheran en su tesis de doctorado (2012). Abordó, desde una perspectiva etnográfica en el período 2008-2011, las intersecciones de las experiencias formativas escolares y familiares y, las transiciones laborales de jóvenes inmigrantes nacidos en Bolivia y Paraguay e hijos de inmigrantes procedentes de esos dos países, que viven en un barrio de la zona sur de la ciudad de Buenos Aires y que asisten a dos escuelas públicas de nivel medio ubicadas en él. Específicamente, en cuanto a jóvenes migrantes bolivianos/as, Beheran estudió aquellos/as que formaban parte del mundo de la producción textil. Concluyó, que en las familias bolivianas cuyos hijos/as asistían al nivel medio parecerían tener una visión menos crítica respecto de la escolaridad de sus hijos/as. Y si bien, las familias migrantes bolivianas le dan a la educación formal una gran importancia, las complejas situaciones de desigualdad social que atraviesan, llevaron a que las mismas intentaran persuadir a sus integrantes más jóvenes, y en ocasiones 
a obligarlos, para que trabajasen junto a sus padres en actividades cuya formación ya habían recibido, en sus hogares (trabajo textil).

En síntesis, según todo lo expuesto se puede observar en primer lugar que, en ninguno de los dos ejes temáticos se abordó directamente el análisis de la incidencia del contexto histórico y la territorialidad periurbana platense en las trayectorias escolares de jóvenes que provienen de familias migrantes bolivianas que se dedican a la producción de hortalizas desde el paradigma constructivista. Es decir, si bien los estudios sobre el periurbano platense dieron cuenta de algunas características del contexto y la territorialidad, no avanzaron específicamente sobre el análisis de las trayectorias escolares de los agentes que habitan ese territorio en el contexto histórico seleccionado, mientras que, los estudios sobre escolaridad en el nivel medio de los/as migrantes bolivianos/as en Argentina dieron cuenta de interrupción de sus trayectorias, pero no ahondaron en la incidencia del contexto histórico y la territorialidad en la escolaridad de estos/as jóvenes de familias migrantes.

En cuanto al marco teórico que orienta el presente trabajo, está centrado en la propuesta de Bourdieu denominada constructivismo estructuralista, con la cual se busca superar la falsa dicotomía objetivismo/ subjetivismo. Por estructuralismo o estructuralista, el autor entiende que existen en el mundo social mismo, y no solamente en los sistemas simbólicos, el lenguaje, mito, etc., estructuras objetivas, independientes de la conciencia y la voluntad de los agentes, que son capaces de orientar o de coaccionar sus prácticas o sus representaciones. Mientras que por constructivismo, quiere decir que hay una génesis social de una parte de los esquemas de percepción, de pensamiento y de acción que son constitutivos de lo que llamamos habitus, una realidad que se construye con acciones humanas que no solo es estructura condicionada (Bourdieu, 1988).

Con respecto a la dimensión de análisis de las trayectorias, se adopta un enfoque teórico-metodológico que pretende superar a los teóricos de la acción, pero sin eliminar al agente, como a los teóricos de la determinación social, reconociendo los efectos que la estructura ejerce sobre el agente y a través de él. En función de ello, pretende apartarse tanto de las teorías que conciben a la acción como el producto del cálculo racional de agentes libres, como de aquellas que definen la praxis social como derivación de las determinaciones estructurales. Por lo tanto, se busca poner en significación la complementariedad de ambas teorías, partiendo de los principales aportes teóricos de Pierre Bourdieu $(1988$; 2011). Para así sugerir las trayectorias como concepto mediador, ya que posee una potencialidad para unir en el análisis la historicidad de los procesos sociales, las constricciones estructurales y la agencia de los agentes (Waisman, 2011).

En tanto que al hablar de estrategias, también se retoma a Bourdieu (2011) quien las conceptualiza como las prácticas por medio de las cuales los/as agentes individuales o colectivos tienden, consciente o inconscientemente, a conservar o aumentar su patrimonio, para así conservar o mejorar su posición en la estructura de relaciones de clase.

Mientras que, para definir a la territorialidad se toma a Rodríguez Valbuena (2010) quien sostiene que la misma es: “...el grado de control de una determinada porción de espacio geográfico por una persona, un grupo social, un grupo étnico... un estado" (Montañez, 1997). Este concepto se complementa con el análisis de Lobato Correa (1996), quien hace referencia al conjunto de prácticas y a sus expresiones materiales y simbólicas capaces de garantizar la apropiación y permanencia de un determinado territorio por un determinado agente social o Estado y los diferentes grupos sociales. En 1998 Montañez complementa la definición al señalar que la territorialidad es una definición derivada del concepto de territorio y unida a la de Estado. Es la acción que consolida la pertenencia y el desarrollo de identidad de un Estado o de una persona sobre un espacio, es el nivel de dominio y de poder que es posible ejercer sobre el mismo, "se asocia con apropiación, con identidad y afectividad espacial, se combina definiendo territorios apropiados: de derecho, de hecho y afectivamente".

Por último, en este trabajo cuando se hace referencia al contexto histórico, se remite a los acontecimientos y procesos políticos, económicos, sociales y culturales que influyen en un determinado tiempo: esto es, en su 
época. En este sentido, la época a la que aludimos si bien se circunscribe a la cohorte de 2011-2017, se adelanta a la primera década del siglo XXI, ya que la historia es un proceso de larga duración, y en consonancia con esto los cambios políticos, económicos y sociales vivenciados por los/as agentes seleccionado/as para este trabajo se produjeron a partir del siglo XXI.

\section{Metodología y fuentes}

La investigación que se ha propuesto en el presente trabajo es un estudio de casos con el que se pretende describir y explicar. La metodología y fuentes, se basó ante todo en el uso de fuentes orales inéditas, para ello, se partió de la historia oral. A su vez, se utilizaron fuentes escritas primarias y secundarias. La estrategia metodológica que se privilegió aquí fue de carácter cualitativa, ya que la misma permitió acercarse a la realidad de los/las jóvenes estudiantes posibilitando documentar sentidos sobre su trayectoria escolar que no hubieran sido posibles comprender sólo analizando las estadísticas y documentos de la institución (Rockwell, 2009; Guber, 2001). A su vez, esta estrategia, se combinó en menor sentido, con una metodología cuantitativa con el objetivo de profundizar el conocimiento y no de validar los datos ${ }^{4}$.

En cuanto a la elección de partir desde la historia oral, fue porque la misma implica reconocer y practicar procedimientos de verificabilidad y rigor documental de la propia historiografía clásica; es decir, trabajar tanto en el campo como en los archivos, y de este modo obligar a la "verdad" escrita y fija de los documentos de las instituciones a confrontarse con las múltiples "verdades" que existen afuera, en el mundo más allá de las puertas (Flier y Portelli, 2018).

Asimismo, la decisión de elegir la historia oral, se debió también a que, las fuentes orales permiten recoger información sobre poblaciones o clases sociales sin escritura, de colectivos excluidos o subrepresentados en la documentación escrita disponible. En síntesis, las fuentes orales son, por lo tanto, condición necesaria para la historia de las clases no hegemónicas (Portelli, 2015 y 2016).

En cuanto a las técnicas de la metodología cualitativa, se realizaron entrevistas en profundidad (semiestructuradas) y observación participante a 21 jóvenes y 5 familias, a partir de una muestra teórica intencional, por bola de nieve por saturación y, a su vez, se realizaron encuestas a todos/as los/as jóvenes. Asimismo, se utilizaron como fuentes primarias diversos periódicos. A partir de este conjunto de fuentes, se reconstruyó la historia del periurbano platense (contexto histórico), la territorialidad y las trayectorias escolares de los/ as jóvenes.

Mientras que, para la metodología cuantitativa, se utilizó como fuente primaria los datos estadísticos de la Escuela Media Pública, elegida en el periurbano hortícola platense. Debido a que, las instituciones educativas son productoras de información de base que luego se utiliza para componer la estadística educativa, se gestionó y logró la autorización para revisar los archivos con documentación de la institución para acceder a información sobre inscripciones, asistencias y calificaciones de los/as alumnos/as, como también datos ocupacionales, demográficos y educativos de los padres y las madres de los/as alumnos/as.

\section{ACERCA DEL CONTEXTO HISTÓRICO Y LA TERRITORIALIDAD DEL PERIURBANO HORTÍCOLA PLATENSE}

Siguiendo a Benencia \& Quaranta (2005: p 1), quienes sostienen que:

\footnotetext{
“en lo rural se profundizó en la última década el abordaje de la dimensión espacial de los fenómenos sociales y su impacto en las características de los mismos y, estos desarrollos incorporan a sus esquemas analíticos la especificidad del tiempo y del espacio para dar cuenta de los procesos sociales, los cuales se encuentran necesariamente imbricados en escenarios locales, que deben ser considerados como un componente tan significativo como las tendencias que exceden esos espacios a la hora de explicar dichos procesos"
} 
es que se consideró pertinente en este trabajo analizar algunas dimensiones sobre el contexto histórico y la territorialidad del periurbano hortícola platense ya que los mismos inciden en las trayectorias de sus agentes.

Por lo tanto, dar cuenta de las características singulares del contexto histórico y la territorialidad en la cual se inserta la unidad de análisis seleccionada, es relevante, puesto que siguiendo a Bourdieu, el contexto histórico y la territorialidad entre otras, son dimensiones que inciden en las trayectorias de los/as jóvenes seleccionados/as.

\section{El contexto histórico periurbano hortícola platense}

Para señalar los acontecimientos y procesos políticos, económicos, sociales y culturales que incidieron durante el período seleccionado (contexto histórico) 5 para el trabajo aquí desarrollado, se retoma la propuesta de Lemmi (2011) quien periodizó la formación del cinturón hortícola plantense. A su vez, en esta investigación interesa rescatar una parte de la historia del tercer período denominado por Lemmi como la horticultura platense en expansión e intensificación. Específicamente, se describirá a partir de la historia de la intensificación (1970-80), puesto que, durante ese período fue que se realizó el recambio étnico al comenzar a establecerse los/as migrantes bolivianos/as que forman parte de los antecesores que se analizan aquí.

\section{La historia económica, política y social de la horticultura platense (1970-2017)}

A nivel territorial local, los/as jóvenes que son objetos de este estudio, forman parte de un proceso mayor que viene gestándose desde la década de los 70 '.

Antes, se hace necesario mencionar brevemente que la historia de la horticultura platense se conformó por diferentes oleadas migratorias. En sus inicios los/as primeros/as migrantes provenían de Italia, España y Portugal, con el saber propio de su lugar de origen ya que muchos eran trabajadores de la tierra. Luego, comenzaron a migrar santafesinos/as y nativos/as de otras provincias del norte de la Argentina también de origen agricultor (Lemmi, 2014).

Por último, a partir de los $70^{\prime}$ comenzaron a arribar desde el sur de Bolivia familias de origen campesino para asentarse en enclaves étnicos en distintos puntos del país, del cual la horticultura platense fue y es uno de ellos (Ringuelet, Cacivio \& Simonatto, 2006; Archenti, 2008; Attademo, Ringuelet, \& Salva, 2005; Attademo, 2009; Lemmi, 2014; Lemmi y García, 2018). De este modo, estas familias desarrollaron un comportamiento propio (disímiles al de los/as pobladores de los países de origen y del de los/as de destino), que consecuentemente les permitió enfrentar de una manera singular las consecuencias de las crisis económico-políticas que se produjeron en ambos territorios nacionales. Arribaron al trabajo acompañados de todo el núcleo familiar, y emprendieron su camino de ascenso social, proceso que ha sido denominado ' escalera boliviana"' (Benencia, 2005). En este sentido, Benencia cuando se refiere a la escalera boliviana, está haciendo alusión a una "escalera" del ascenso social que vislumbró en sus estudios sobre los horticultores migrantes de origen boliviano en la década del $80^{\prime}$. El autor constató para esos años la existencia de una "escalera boliviana" de ascenso social y económico experimentado por dichos agentes, a través del paso de peón a mediero y de mediero a arrendatario y por último al de propietario (Benencia, 1999).

En la década del 90', en el periurbano hortícola platense a estos/as migrantes de origen boliviano, la convertibilidad les permitió ahorrar y enviar remesas en dólares a su país de origen, siendo esta una de sus estrategias para ir transitando esta escalera de ascenso social que los llevó desde el peldaño de peón a mediero, y postcrisis 2001 del peldaño de mediero a arrendatario, empero ya para esta época, sin alcanzar el peldaño de propietario de la tierra (Hang, et al, 2007; García, 2011). En este caso, para el siglo XXI están también las investigaciones de Attademo, Waisman \& Rispoli (2011), quienes sostuvieron que otra estrategia de reproducción de las familias bolivianas fue la organización familiar de la actividad económica en 
la horticultura, esto es, haber sido simultáneamente una unidad de producción y reproducción, soportando la autoexplotación para poder realizar acumulación de capital pero siempre dentro de la quinta y sin poder acceder a la propiedad de la tierra.

Como ya se había señalado recientemente, las anteriores oleadas migratorias de los 40' y 60 ', desplegaron estrategias que llevaron a los/as migrantes a recorrer lo que Lemmi (2014) denominó la ' escalera gringa '. Según la autora, la primera generación de migrantes gringos italianos/as, portugueses/as y españoles/as comenzaban trabajando de peones, hasta que sus sucesivas generaciones alcanzaron el peldaño de propietarios patrones hasta incluso convertirse en arrendatarios saliendo de la producción primaria. Es decir los/as nietos/ as de esos primeros/as peones a través de la educación pública adquirieron credenciales educativas para desvincularse de la producción primaria ${ }^{6}$.

Volviendo al período seleccionado para este trabajo, en el caso de los/las jóvenes seleccionados/as en este estudio, el contexto histórico (acontecimientos y procesos de su época) vivido por los/as mismos/as y sus familias, a diferencia del vivido por las generaciones de la "'escalera gringa' ", les habilitó otro tipo de estrategias para el desarrollo de una movilidad social ascendente más allá del espacio productivo ${ }^{7}$.

Es decir, a diferencia de las estrategias señaladas en los estudios abordados en el estado del arte sobre el periurbano hortícola platense, aquí se pone en foco a como la nueva coyuntura postcrisis del año 2001postdevaluación de 2002, restringió la posibilidad de acceso a la tierra pero habilitó a las familias migrantes bolivianas, a través de otras políticas emanadas desde el Estado, diferentes estrategias, es decir otras prácticas por medio de las cuales tendieron, consciente o inconscientemente, a conservar y aumentar su patrimonio y así cumplimentar sus metas de mejora de la calidad de vida. En este sentido, se recupera como la conflictividad de los años de crisis forzó la implementación de una serie de programas de transferencias de ingresos condicionados y otras políticas destinadas a los sectores vulnerables, entre los que se encontraba la población migrante. En política migratoria en el año 2003, se sancionó la ley № 25.871 que buscaba promocionar una mayor integración de los/as inmigrantes, caracterizándose por el reconocimiento de los derechos humanos de estos agentes que arriban de otros países.

Con respecto a la política educativa, en 2006 se sancionó la ley Nacional de Educación No 26.206. Se estableció garantizar el acceso, permanencia y egreso de todos los niveles del sistema educativo a todos/as los/as residentes del país, sean argentinos/as o inmigrantes, convirtiendo al nivel de educación media en obligatorio (Beherán, 2012) ${ }^{8}$.

Por otro lado, en el año 2009 el gobierno Kirchnerista en búsqueda de consensos, buscó fortalecer la participación de las clases subalternas y realizó un "giro progresista” a través del aumento del salario mínimo, aumento al Plan Alimentario Nacional, la creación del 1.000 cooperativas y fundamentalmente, con la creación de la Asignación Universal por Hijo (AUH) (Varesi, 2011).

Sumado a todo esto, si bien el periurbano platense es considerado para el año 2010 la región hortícola más importante del Cinturón Verde Bonaerense, con el mayor número de quintas y superficie hortícola (García \& Le Gall, 2010), la situación de vulnerabilidad social en la que vive la mayoría de los/las productores/as migrantes bolivianos/as durante la primera década del siglo XXI es insoslayable (Ver Figura $\left.\mathrm{N}^{\circ} 1\right)^{9}$. 


\section{Figura $\mathrm{N}^{\circ} 1$}

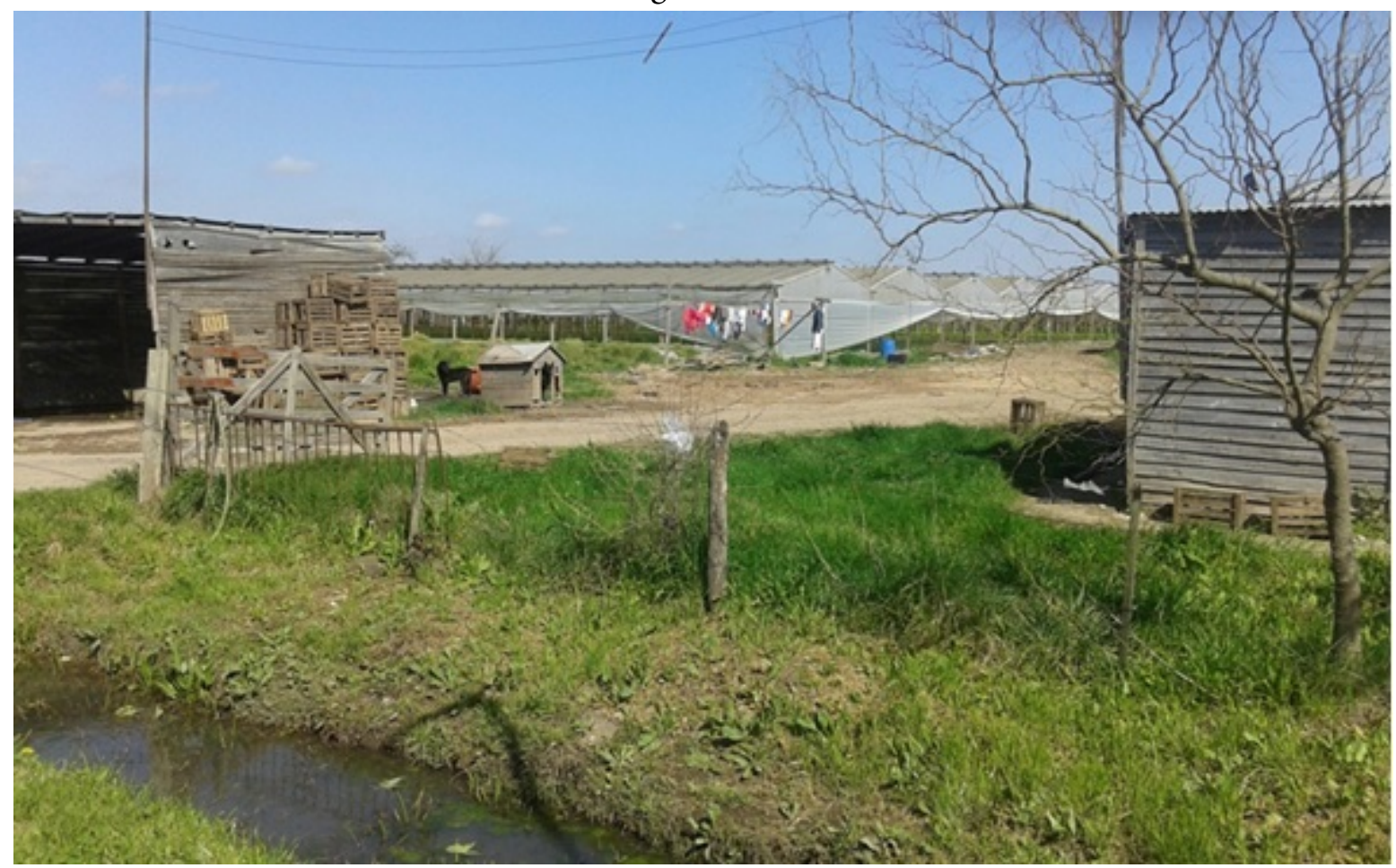

Fuente: Foto tomada durante el trabajo de campo.

Da cuenta de esta situación de vulnerabilidad social en la que viven lo/las migrantes bolivianos/as por ejemplo, cuando en abril de 2017 se agruparon y presentaron un proyecto de ley al Congreso de la Nación para crear un fondo fiduciario destinado al otorgamiento de créditos que posibilite la compra de tierra a pequeños productores ${ }^{10}$.

También reclamaron una Ley de Emergencia para el sector agrícola. Aquí participaron productores/as del cinturón hortícola de La Plata con el lema "la problemática por el acceso a la tierra es común a todos"11.

Puede verse que la estrategia de vida que aspira a la escalera boliviana a través del acceso a la propiedad de la tierra no está siendo viable en este contexto histórico particular (Benencia \& Quaranta, 2018).

Por lo tanto, el contexto histórico actual descripto en el que habitan los/as migrantes bolivianos/as en el periurbano hortícola platense es desfavorable en lo que respecta al acceso a la propiedad de la tierra. Esto implica, además, como será detallado más adelante, que al no ser propietarios de la tierra en la que trabajan no es rentable realizar inversiones en ella, por lo cual viven en las condiciones que aporta el dueño de la tierra: casillas de madera con precaria dotación de servicios.

Es por esta razón que para el caso de los/las jóvenes objeto del presente trabajo, puede vislumbrarse un cambio en sus estrategias de vida para alcanzar una movilidad ascendente a través de la educación en el nivel medio, para luego bifurcar el último peldaño de la clásica escalera boliviana hortícola, enunciada por Benencia en 1999, e ingresar a un mercado laboral ajeno a la horticultura mediante credenciales educativas que los/as jerarquicen (Benencia \& Quaranta, 2018; Morzilli, 2019).

En todas las entrevistas, las familias de estos/as jóvenes contaron sus deseos de superar su historia campesina, y que a través de la $\mathrm{AUH}$, la escuela media pública y las leyes que amparan a los/as migrantes, buscan mediante la educación secundaria superar esta historia de vida (Morzilli, 2019).

El relato de una madre dando cuenta de ello:

... aquí a la Argentina entré a los 18 años. Pero salí de mi casa a los 15 años a trabajar; trabajaba para la gente y no pude seguir estudiando...pero yo prefiero que estudien y que busquen un trabajo que sea otra cosa... Yo digo está bien, pero ellas tienen 
que estudiar para... si no estudian ¿de qué van a vivir?... Si no hacen lo mismo que nosotros... y ellas no quieren y nosotros tampoco..." (Entrevista realizada a una madre durante el primer semestre de 2017).

\section{Territorialidad y condiciones de vida en el periurbano hortícola platense}

Existe una serie de características que unifican a los/as jóvenes. Es decir, como ya se ha indicado viven en condiciones de vulnerabilidad social puesto que, en su mayoría los/as jóvenes relataron que vivían en casillas cuyo material predominante en las paredes exteriores era la madera, con techo de chapa de metal y pisos de cemento. En estos casos la ubicación del baño estaba fuera de la vivienda; en tanto que, la composición del mismo constaba de inodoro sin arrastre de agua (balde, tacho) y no tenían animales de granja para consumo del hogar o la venta. Mientras que, con respecto a la AUH en su totalidad los/as 21 entrevistados/as dijeron que eran perceptores/as de la misma. Además trabajan en la quinta todos/as los/as jóvenes.

Relatos que dan cuenta de lo descripto:

“... mnnn no, no es de ladrillo mi casa... es tipo una casilla... con paredes de madera...”' (Entrevista realizada durante el primer semestre en 2017).

“... y... empecé a ayudar a mi familia en la quinta desde los 10 años...lo que generalmente hago es cosechar y llevar la verdura a los galpones...más o menos le dedico 3 horas 3 veces por semana...” (Entrevista realizada durante el segundo semestre en 2017).

Específicamente los varones realizan tareas productivas y las mujeres tareas productivas y de cuidado. Tanto para varones como para mujeres las condiciones de trabajo son arduas. Esto hace que el sentido que construyen sobre el trabajo en la quinta sea negativo.

Puede observarse esto a través de los siguientes relatos:

"No, no me gusta, es sucio, agotador, aburrido, a veces no pagan lo suficiente." (Entrevista realizada durante el primer semestre de 2016).

"No me gusta porque tenés que trabajar todo el día y es agotador." (Entrevista realizada durante el primer semestre de 2017).

Aun viviendo en situación de vulnerabilidad y trabajando, los/as jóvenes seleccionados/as sostienen trayectorias escolares de permanencia y egreso en el nivel medio.

El rol de las madres y padres es muy relevante en esta cuestión (esto también ya lo han señalado Cerletti (2014) para otras poblaciones). Puesto que, a partir de todo el trabajo de campo, se puede saber que el nivel educativo primario de la mayoría de sus padres-madres es incompleto, sin embargo esto hizo que las familias actúen acompañando y controlando las trayectorias escolares de sus hijos/as. ${ }^{12}$

Así narraban unas madres:

“...y sí, me hubiese gustado estudiar para maestra... lo que pasa que allá era, que se yo, me quedaba lejos para ir... no había para comprar útiles ... quiero que mis hijas que consigan un mejor trabajo ... que estudien... la más grande me trajo buenas notas este año... bue... también tiene que traer buenas notas porque si no, no se va a ir... porque está con eso, con el viaje de egresados...pero me trajo muy buenas notas este año... re bien... sí, ella va bien... la del medio es la que me da trabajo... está en una edad... no se... que con la más grande no me pasó eso eh... ella es más callada, que se yo... esta no, ella es... ahora me dice, me estaba reclamando me vino de la escuela reclamando hoy porque no la dejo... no me dejas salir a ningún lado, porque no? ... y es que ya le pillé ... ve... y entonces le digo a mi marido, vamos a traerla de la escuela porque... entonces la fuimos a traer y no le dije nada..." (Entrevista realizada a una madre durante el segundo semestre de 2016).

“... en mi caso yo hice hasta $5^{\circ}$ grado... terminé mi escuela y no sé, va yo me acuerdo que allá en Bolivia se pagan las libretas...que terminen la escuela si o si... que no pasen lo que pasé yo... cuando tienen ellas tiempo libre ayudan en la quinta... ahora, a lo menos ahora en invierno ya casi no ayudan porque hace frío, y yo también no las saco... otra cosa que quieren tareas, o tienen que a veces estudiar para el examen, o algo, ellas ya no van a ayudar a la quinta... ahora en invierno no, no me ayudan casi...cuando ellas tienen que hacer sus cosas de la escuela, yo las dejo a mis hijas... yo jamás preferiría que vayan a hacer cosas de la quinta antes que de la Escuela..." (Entrevista realizada a una madre durante el segundo semestre de 2016). 
Cabe destacar que, a su vez todo esto es posible, por las características particulares del territorio, es decir, el conjunto de prácticas y expresiones materiales y simbólicas que garantizan la apropiación y permanencia de este determinado territorio (territorialidad). Esto es, porque no hay dispersión ya que los/as jóvenes viven cerca de la escuela y además, trabajan en donde viven. Sumado a esto, los/as pares con quienes se rodean comparten proyectos en común al ser también migrantes bolivianos/as que trabajan en la horticultura ${ }^{13}$.

En conjunto todas estas características y singularidades de la territorialidad confluyen junto al contexto histórico y van explicando en que, como se describirá en el apartado siguiente, puedan sostener trayectorias escolares paralelamente a sus labores productivas sin que estas dificulten su escolaridad y con el objetivo de culminar el nivel medio y acceder a los estudios superiores.

Entonces, estas características del contexto histórico y la territorialidad del periurbano hortícola platense dan cuenta del refuerzo para lograr una bifurcación en el último peldaño de la escalera boliviana.

Debe subrayarse que todos/as los/as jóvenes analizados/as aquí (tanto mujeres como varones), poseen interés en estudiar para salir de la actividad productiva primaria, esto pudo notarse a través de los relatos sobre el trabajo en la quinta, como también por los relatos de sus madres para que sus hijos/as sigan estudiando ${ }^{14}$.

Retomando los análisis y reflexiones anteriores se puede sostener que los/as jóvenes seleccionados/as en el presente trabajo se asentaron en áreas de producción hortícola del periurbano hortícola platense y desarrollaron así un comportamiento propio.

Éste se destacó por dos estrategias: la inserción en la horticultura y por la realización de esfuerzos por parte de los/as jóvenes y sus familias para que completen sus estudios de nivel medio.

A través del trabajo de campo, pudo identificarse como estos/as jóvenes despliegan constantes esfuerzos para transitar por una escalera de ascenso social diferencial a la hortícola, al igual que las investigaciones de Attademo, Waisman \& Ríspoli, empero, aquí ya buscan una alternativa a la horticultura.

Podemos ver que al poner en relación las características del contexto histórico y la territorialidad en donde habitan y transitan éstos/as jóvenes con el resultado de las trayectorias escolares, se hace posible sostener que lo descripto en el apartado referido al contexto histórico y a la territorialidad, serían dimensiones explicativas que dan cuenta del resultado de las trayectorias escolares descriptas en este apartado, esto a su vez, estaría indicando las diferencias con los resultados de las investigaciones sobre educación media y migración boliviana anteriormente señaladas, ya que el contexto y la territorialidad aquí abordado es diferente al de los respectivos estudios.

\section{LOS TRAYECTOS ESCOLARES DE LOS/AS JÓVENES Y LOS SENTIDOS SOBRE LA EDUCACIÓN}

\section{Las trayectorias escolares}

Como se ha enunciado en la introducción del presente trabajo con respecto a la educación media, en la primera parte del siglo XXI se dio la masificación del ingreso a dicho nivel y la obligatoriedad del mismo. Sin embargo, a pesar de este proceso, las mejoras en la matriculación del nivel educativo medio no tuvieron en paralelo mejoras en las tasas de egreso.

Por lo tanto, en relación a esto, cabe mencionar brevemente la historia del nivel medio en Argentina. En este sentido retomamos la periodización de Guerra (2012), quien sostuvo que existió entre el siglo XIX y XXI, un primer período donde la educación media era humanística y religiosa para la elite; luego un segundo período en el cual existió una estructuración del sistema educativo medio para formación de la elite; un tercer período en el que la educación media fue destinada para la formación productiva, la nacionalización y docencia; un cuarto período donde la educación media apuntó al acceso de las clases medias a la educación de escuelas técnicas de artes y oficios; un quinto período en el que el objetivo de la educación media se orientaba a la formación para el trabajo y donde se inició el camino hacia la masificación; un sexto período cuyo objetivo 
era la educación media para la formación de técnicos; un séptimo período en donde la educación media pública contaba con una limitación de las libertades políticas de los educandos/as; un octavo período en el cual la estructuración de la educación media pública tenía como fin la vía democrática; un último período en el que la educación media pública tuvo como finalidad en el marco de la masificación incorporar a los sectores populares a través de su obligatoriedad.

Contradictoriamente durante todos estos períodos en los cuales se dieron cambios, según Acosta (2011), la masificación de la escuela media en la Argentina presentó ciertas especificidades: esto fue que, el aumento de su matrícula se acompañó de un importante índice de desgranamiento desde sus orígenes. La autora concluyó, que la masificación de la escuela media en la Argentina se produjo desde una matriz de incorporación y expulsión en forma simultánea y que estos procesos están vinculados con que, el modelo institucional que la escuela de dicho nivel sigue teniendo lógicas intrínsecas que responden a los fines originales para la que fue creada.

Entonces, en cuanto a la matrícula y a las tasas de asistencia, el Ministerio Nacional de Educación (2013), señaló que el Censo de 2010 dio como resultado para las tasas de asistencia que un 15\% de la población que se encontraba en el tramo de 12-14 años no estaban asistiendo al ciclo básico de la escuela secundaria. Mientras que, para el ciclo posterior el 46\% de la población de 15-17 años no asistía al ciclo orientado.

Ahora bien, en lo que respecta a la educación media y los/as jóvenes de familias migrantes bolivianas, los estudios concluyen que los/as jóvenes de estas familias interrumpen sus trayectorias, ya sea por situaciones de discriminación como por su situación laboral (Domenech, 2005; Nobile, 2016; Salva \& Lago, 2012; Binstock y Cerrutti, 2012; Beheran, 2012; Diez, 2014; Gavazzo, Beheran \& Novaro, 2014 \& Novaro, 2016)

Entonces, a partir de esta bibliografía, fue que se produjo el acercamiento a una Escuela de nivel medio y se realizó una muestra teórica intencionada de 21 jóvenes alumnos/as de familias migrantes bolivianas a quienes se entrevistó (de manera semi-estructurada) en profundidad ${ }^{15}$.

Con el objetivo del acercamiento a la Escuela durante el ciclo lectivo de 2016 ya para realizar entrevistas y comenzar con la observación participante y, luego de varios encuentros en el contexto de talleres en clase, de análisis de fuentes primarias de los registros de inscripción de la Escuela y, de realizar una muestra teórica intencional, uno de los alumnos al relatar su trayectoria escolar dijo:

“...nací en Bolivia, vine con mis padres y hermanos en 2013... hice toda la primaria y el primer y segundo año del secundario allá, en Bolivia...vinimos directamente acá y comencé en esta Escuela en 2011 el $3^{\circ}$ año del secundario..." (Entrevista realizada en la Escuela durante el segundo semestre en 2016).

Otra alumna relató:

“... allá en Mendoza conoció a mi mamá... yo soy mendocina...hice la $3^{\circ}$ salita del jardín y, desde primer grado hasta séptimo en Mendoza en una Escuela pública...después por trabajo nos mudamos acá, pero hice desde $1^{\circ}$ año hasta $3^{\circ}$ año del secundario en una Escuela de Olmos, pero como no me gustaba me cambié a ésta Escuela... ahora estoy cursando 60..." (Entrevista realizada en la Escuela durante el segundo semestre en 2016).

Algunas historias escolares de otros/as alumnos y alumnas:

“...soy de Bolivia, tengo 15 años y estoy cursando $4^{\circ}$ año del secundario. Nos vinimos de Bolivia a vivir acá a mis 11 años y empecé $6^{\circ}$ grado del primario en esta misma Escuela... Siempre estudié en la Escuela pública...” (Entrevista realizada en la Escuela durante el segundo semestre en 2016).

“... Comencé el jardín de infantes pero por lejanía lo abandoné, y luego empecé $1^{\circ}$ grado del primario en esta Escuela...” (Entrevista realizada en la Escuela durante el primer semestre en 2016).

“...nací acá... en Argentina, pero mi mamá y mi papá son bolivianos...cuando tenía 5 años me mandaron a la última salita del jardín en una Escuela de Salta... porque soy de allá... Nos mudamos a Buenos Aires y empecé $2^{\circ}$ grado en el primario de esta Escuela...Repetí en $2^{\circ}$ año del secundario...Ahora estoy en $4^{\circ}$ año del secundario..." (Entrevista realizada en el hogar durante el primer semestre en 2016). 
“... nací en Bolivia, pero vinimos hace mucho a Argentina... fui a al jardín desde la $2^{\circ}$ salita de jardín hasta primer grado del primario en una Escuela pública de los Hornos... empecé en esta Escuela en $3^{\circ}$ grado en el primario...y seguí acá el secundario... estoy en $4^{\circ}$ año y tengo 17 años..." (Entrevista realizada en la escuela durante el primer semestre en 2017). “... nací acá en el $2000 \ldots$ no fui al jardín y empecé directo el primario en esta Escuela... estoy en $3^{\circ}$ año..." (Entrevista realizada en la Escuela durante el primer semestre en 2017).

Luego de todo el trabajo de campo observamos que 17 jóvenes alumnos/as dieron cuenta de trayectorias escolares reales que siguen a las teóricas, esto es según Terigi (2008), que expresan itinerarios en el sistema educativo que siguen la progresión lineal prevista por éste en los tiempos marcados por una periodización estándar.

Cuatro jóvenes alumnos/as dieron cuenta de trayectorias escolares reales que difieren de la teórica. Estas fueron, tres con situaciones de repitencia y una con situaciones de interrupción y luego de retorno.

Algo que se destaca como exitoso es que no hay una historia de muchas repitencias en las trayectorias, y escasa interrupción.

Otra mirada sobre las trayectorias: las asistencias y las calificaciones escolares

A) En relación a la cantidad de inasistencias, la tendencia fue en:

-ocho casos disminuyeron;

-dos casos se mantuvieron;

-y en 11 casos aumentaron.

En los casos que las inasistencias aumentaron los/as jóvenes manifestaron que fue por enfermedad ${ }^{16}$.

B) Con respecto a las calificaciones escolares:

-en seis casos aumentaron, en tanto que se verificó en los registros de calificaciones un aumento de sus notas;

-En nueve casos se mantuvieron;

-mientras que en cinco casos disminuyeron.

En los casos en que las calificaciones escolares disminuyeron, los/as jóvenes manifestaron que fue porque les costaban las materias cuyas temáticas no eran de su interés ${ }^{17}$.

Debe recordarse que éstos/as jóvenes desde los 10-15 años aproximadamente le dedican alrededor de entre 3 y 4 horas diarias al trabajo en la quinta.

Diferentes relatos de alumnos/as:

“...más o menos 3 horas diarias todos los días menos los sábados...” (Entrevista realizada en la Escuela durante el segundo semestre en 2016).

“... y... empecé a ayudar a mi familia en la quinta desde los 10 años...lo que generalmente hago es cosechar y llevar la verdura a los galpones...más o menos le dedico 3 horas 3 veces por semana...” (Entrevista realizada en la Escuela durante el segundo semestre en 2017).

“... ayudo desde los 10 años todos los días medio día a mis padres en la quinta...más que nada cargo, limpio y planto...” (Entrevista realizada en la Escuela durante el segundo semestre en 2017).

$\mathrm{Al}$ relacionar los relatos sobre sus trayectorias escolares, sus trayectorias productivas y el análisis estadístico de sus asistencias y calificaciones puede constatarse que las labores productivas no actúan en detrimento de su trayectoria escolar, en estos casos se dan dinámicas diferentes a las que señalaron Garatte (2015) y Nobile (2016), puesto que estas autoras encontraron que el rendimiento escolar baja, las asistencias aumentan y las trayectorias escolares de jóvenes migrantes que trabajan se interrumpen.

Por lo tanto, al analizar las trayectorias ${ }^{18}$ escolares, de éstos/as jóvenes y si se comparan estas con las trayectorias escolares de sus madres y padres que no alcanzaron el nivel medio, pueden ser consideradas las trayectorias de estos/as jóvenes, tanto por ellos/as y como por sus familias, como un éxito. En este sentido estos resultados serían diversos a los encontrados por las mencionadas investigaciones que observaron que, las trayectorias de jóvenes de familias migrantes bolivianas tenían trayectorias en el nivel medio interrumpidas (Domenech, 2005; Nobile, 2016; Salva \& Lago, 2012; Binstock y Cerrutti, 2012; Beheran, 2012; Diez, 
2014; Gavazzo, Beheran \& Novaro, 2014 \& Novaro, 2016). Es aquí donde se hace necesaria la pregunta del contexto histórico y la territorialidad que le dan singularidad a los casos aquí abordados.

Ergo, debe tomarse en cuenta a su vez, retomando el paradigma constuctivista-estructuralista y la categoría de trayectoria, que los sentidos que le otorgan a la educación son relevantes en la construcción de sus propias trayectorias, pero a su vez, los mismos no dejan de estar influenciados por el contexto histórico y la territorialidad como ya se ha señalado.

Sobre los sentidos que le otorgan a la educación

Con respecto a los sentidos que los/as jóvenes le otorgan a la educación, pudo verse que poseen una percepción sobre la misma en el nivel medio como un pasaje necesario para obtener credenciales educativas que les permitirán lograr una movilidad social ascendente.

Narrativas de algunos alumnos/as:

' '... la educación en la Escuela significa aprender muchas cosas... saber... Para... Para así cuando termine sexto pueda arrancar algo, lo que quiera, lo que yo quiera estudiar o lo que quiera... me gustaría ser profesora de jardinería...eh... [Refiere a maestra jardinera, docente de Nivel Inicial] ' ' (Entrevista realizada durante el segundo semestre de 2016).

"Estudiar es aprender más... para luego poder estudiar otra cosa... vivir de otra cosa... para no trabajar como trabajan mis padres... trabajan mucho y ganan poco..." (Entrevista realizada durante el primer semestre de 2017).

"... estudio para ser alguien más allá... para tener un trabajo ideal...un trabajo en el que tenga derechos, porque... no quiero trabajar en negro así vio... algo con derechos... con seguro social..." (Entrevista realizada durante el primer semestre de 2017). “... estudiar para mejorarse, para en un futuro tener por ahí una mejor calidad de vida...” (Entrevista realizada durante el primer semestre de 2016).

Aquí puede verse, lo que se enunció al inicio de este apartado en cuanto a cómo las prácticas institucionales logran operar en los sentidos de los jóvenes. Entonces, todo esto, junto a lo descripto en los anteriores apartados, los/as lleva a construir trayectorias escolares exitosas, en el sentido de que no interrumpen la escuela y que alcanzan el nivel medio a diferencia de sus madres y padres. Es decir, concretan una estrategia que consiste en invertir en la educación para poder salir de la "escalera boliviana hortícola".

De este modo, pretenden transformar la "escalera hortícola boliviana", reconstruyendo una escalera de ascenso social cuyo último peldaño no consista ya en la adquisición de la tierra en propiedad, sino en la obtención de credenciales educativas donde mediante otras ocupaciones y/o profesiones logren la movilidad social ascendente deseada.

Relatos de jóvenes:

“... estudiar para seguir adelante...y mejorar y tener una carrera y seguir estudiando...” (Entrevista realizada durante el segundo semestre de 2017).

“... el estudio para mí sirve para el día de mañana ser otra cosa y trabajar de otra cosa... no trabajar en la

Quinta...” (Entrevista realizada durante el segundo semestre de 2017)

"estudiar en la escuela para mí significa aprender... y luego poder estudiar algo como mecánica o algún otro trabajo mejor

que el de la Quinta...” (Entrevista realizada durante el primer semestre de 2017).

En esta aspiración de una nueva escalera de ascenso social, se puede observar que no es solamente productiva-hortícola, sino que está acompañada por una estrategia de obtención de credenciales educativas.

Es decir, esta escalera que en inicio solo era hortícola, ahora se le suma la dimensión educativa.

Los esfuerzos que realizan para operar el pase de peón a mediero y de mediero a productor-arrendatario, va acompañado por el empeño de pasaje de nivel educativo de éstos/as jóvenes de jardín de infantes (nivel inicial) a primario, de primario a secundario y de éste al terciario-universitario, mientras que el último peldaño consiste en el hacer profesional.

A modo de síntesis, estos resultados dan cuenta que en los casos aquí analizados, todos/as asisten a la escuela, trabajan en la horticultura, son perceptores/as de la AUH y a su vez, la mayoría posee una trayectoria escolar real que coincide con la teórica (con la excepción de dos casos que difieren de la trayectoria teórica). 
En los dos únicos casos de existencia de sobreedad, la misma se dio en un caso en su infancia por razones de lejanía del hogar a la Escuela y, en el otro, por cuestiones de salud.

\section{A MODO DE CIERRE}

Por lo tanto, puede observarse que éstos/as jóvenes seleccionados/as se insertaron en un contexto histórico en donde la educación media se expandió en las últimas décadas del siglo XX e inicios del XXI, acompañando así la generalización de la educación primaria y las mayores demandas educativas de los distintos sectores sociales y productivos, y la extensión de la escolaridad obligatoria con la nueva ley de Educación Nacional No 26.206 que convirtió en obligatorio al nivel medio.

También se vislumbró que estos/as jóvenes, se incorporaron a una sociedad en donde se posibilitó que los/as mismos/as lograsen obtener la $\mathrm{AUH}$, producto de la ampliación del paradigma de protección social, que permitió que niños/as y jóvenes inmigrantes que asistan a la educación pública tengan derecho a su percepción y, a su vez, donde la nueva política migratoria también contempló el reconocimiento de derechos universales a los/as inmigrantes.

Se pudo ver que, este contexto histórico a través de estas políticas públicas se articuló con las historias de estos jóvenes, es decir con los sentidos sobre el trabajo en la quinta como con los sentidos de las familias para que estos/s jóvenes sigan estudiando, y vehiculizó estrategias para que las condiciones de vulnerabilidad social en la que se encuentran, en vez de operar como obstáculo obrasen como dinamizador del deseo de superar la historia productiva y educativa familiar. A este respecto las investigaciones mostraron que la historia de los/ as migrantes del periurbano hortícola platense ha sido una historia de deseos de ascenso social.

Por otro lado, en cuanto a la territorialidad, lo distintivo es que la misma tiene un rol relevante por varios motivos, esto es, hace que no exista dispersión, viven cerca de la escuela, trabajan en donde viven y los/as pares con quienes se rodean comparten proyectos en común al ser también migrantes bolivianos/as que trabajan en la horticultura.

Todo esto enlazado confluye en que puedan sostener trayectorias escolares paralelamente a sus labores productivas sin que estas dificulten su escolaridad.

En lo que respecta específicamente a sus trayectos escolares, de la totalidad de 21 jóvenes, se observó que 4 asistieron y egresaron, en tanto que, 17 asistían al nivel educativo medio con éxito para el período 2017.

Debe subrayarse que los sentidos que le otorgan a la educación también son relevantes al momento de construir sus trayectorias escolares y que en estos inciden ciertas lógicas institucionales del contexto. Pudo verse que estos/as jóvenes poseen una percepción sobre la educación en el nivel medio como un pasaje necesario para obtener credenciales educativas que les permitirán lograr una movilidad social ascendente fuera de la horticultura. En este sentido también está operando la propia historia educativa familiar.

Particularmente, en los casos estudiados se advirtió que la educación media, forma parte de las estrategias de vida para alcanzar el ascenso social.

Por lo cual, estos/as jóvenes despliegan estrategias vinculadas al empeño del pasaje de nivel educativo de jardín de infantes (nivel inicial) a primario, de primario a secundario y de éste al terciario-universitario. Éste último nivel se convertiría en el último peldaño de la " 'escalera boliviana" ' que consistiría en el hacer profesional.

Entonces, a partir de lo expuesto y al poner en relación los acontecimientos y procesos que hacen al contexto histórico con las respectivas políticas públicas enumeradas, los deseos de superar las historias familiares, la territorialidad, los significados sobre el trabajo en la quinta como los deseos de las madres para que sus hijos/as sigan estudiando, con las trayectorias escolares de éstos /as jóvenes, podemos sostener que el contexto histórico experimentado por los/as mismos/as y la territorialidad en la que viven les habilitó posibilidades para desplegar nuevas estrategias más allá del espacio productivo. Todo esto en interrelación con la falta de posibilidades de acceso a la tierra, y el tipo de trabajo productivo característico del periurbano 
hortícola platense inciden para que estos/as jóvenes busquen en la escuela alcanzar credenciales educativas para poder dedicarse a trabajar en otra actividad, abonando a esto los sentidos que elaboran sobre la educación en el nivel medio.

Finalmente, recuperando el marco teórico de Bourdieu ' 'constructivismo-estructuralista' ', y desde la historia oral, se observa aquí que el contexto histórico y la territorialidad son dimensiones que inciden interrelacionándose con otras, en las trayectorias escolares de jóvenes provenientes de familias migrantes bolivianas. Es decir, cada contexto histórico tiene singularidades que implican momentos de ruptura que traen consigo cambios en la vida de los/as agentes, constituyéndose así nudos o puntos de bifurcación que significan ciertas transformaciones en sus destinos. A su vez, estas trayectorias escolares dan cuenta de la unidad entre la historicidad de los procesos sociales, las constricciones estructurales y la agencia de los agentes.

\section{REFERENCIAS}

Acosta, F. (2011). La configuración de la escuela secundaria en la Argentina: tendencias históricas nacionales en el marco de las tendencias internacionales: Modelo institucional y desgranamiento en la escuela secundaria durante el siglo XX. Jornada de la Sociedad Argentina de Historia de la Educación (SAHE). Recuperado de http:// www.sahe.org. ar.

Archenti, A. (2008). Producciones identitarias y relaciones interculturales en el periurbano platense, Mundo Agrario, Nro. 17, segundo semestre.

Attademo, S. (2009). Lazos sociales y estrategias: ¿una opción para las familias hortícolas empobrecidas, Mundo Agrario, 9(17). Recuperado de: http://www.mundoagrario.unlp.edu.ar/article/view/v09n17a09

Attademo, S., Waisman, M. A., \& Rispoli, M. F. (2011). Consideraciones acerca de las posiciones diferenciales en el espacio social rururbano platense. Ponencia presentada en: el X Congreso Argentino de Antropología Social, Universidad Nacional de Rosario, Rosario: Julio.

Barsky, A. (2005). El periurbano productivo, un espacio en constante transformación. Introducción al estado del debate, con referencias al caso de Buenos Aires, Scripta Nova, 9(194), 36.

Beheran, M. (2012). A la vida siempre le tuve curiosidad... Siempre quise aprender y hacer cosas pero mi deseo es volver a mi pais. Intersecciones entre experiencias formativas, transiciones laborales e identificaciones nacionales de jóvenes inmigrantes y descendientes de inmigrantes en la ciudad de Buenos Aires. Tesis Doctoral (Mimeo), Buenos Aires.

Benencia, R. (1999). El concepto de movilidad social en los estudios rurales. Estudios Rurales. Teorias, problemas y estrategias metodológicas. Buenos Aires: La Colmena.

Benencia, R. (2005). Migración limítrofe y mercado de trabajo rural en la Argentina Estrategias de familias bolivianas en la conformación de comunidades transnacionales. RELET-Revista Latinoamericana de Estudios del Trabajo, $10(17), 5-30$.

Benencia, R. (2006). Inserción de inmigrantes bolivianos y mercado de trabajo rural argentino. Familias transnacionales en la conformación de territorios productivos, Geodemos, (11).

Benencia, R. \& Quaranta, G. (2005). Producción, trabajo y nacionalidad: configuraciones territoriales de la producción hortícola del cinturón verde bonaerense, Revista Interdisciplinaria de Estudios Agrarios, Nro. 23, 2 do semestre.

Benencia, R., Quaranta, G. \& Souza Casadinho, J. (Coords.). (2009). Cinturón hortícola de la Ciudad de Buenos Aires. Cambios sociales y productivos. Buenos Aires: CICCUS.

Benencia, R., Ramos, D. \& Salusso, F. (2016). Inserción de horticultores bolivianos en Río Cuarto. Procesos de inmigración, trabajo y conformación de economías étnicas, Revista Mundo Agrario, 17 (36).

Benencia, R. \& Quaranta, G. (2018). La horticultura de "fin" a “medio": nuevas realidades de las familias bolivianas en la horticultura del área metropolitana de la ciudad de Buenos Aires. Revista Migraciones Internacionales. Reflexiones desde Argentina. Recuperado de: http://argentina.iom.int/co/sites/default/files/publicaciones/REVISTA\%20 MIGRACIONES\%20INTERNACIONALES\%20digital\%20final.pdf 
Bertranou, E. (2002). Determinantes del avance en los niveles de educación en Argentina. Análisis empirico basado en un modelo probabilístico secuencial. Tesis de la Maestría en Economía, Universidad Nacional de la Plata, La Plata.

Binstock, G. \& Cerruti, M. (2012). Los estudiantes inmigrantes en la escuela secundaria. Integración y desafíos. Buenos Aires, Unicef.

Bottinelli, L. (2017). Educación y desigualdad. Un repaso por algunos aportes de la sociología de la educación en la Argentina. Revista Sociedad, (37).

Bourdieu, P. (1988). La distinción. Buenos Aires: Taurus.

Bourdieu, P. (2011) The forms of capital. (1986). Cultural theory: An anthology, 1, 81-93.

Cerletti, L. B. (2014). Familias y escuelas. Tramas de una relación compleja. Buenos Aires: Biblos.

Cieza, R. I. (2012). Financiamiento y comercialización de la agricultura familiar en el Gran La Plata: Estudio en el marco de un proyecto de Desarrollo Territorial. Mundo agrario, 12(24).

Diez, M. L. (2014). Procesos de identificación, migración y escolaridad en el sur de la Ciudad de Buenos Aires. Una aproximación desde la dimensión generacional. Ponencia presentada en: AAVV, XI Congreso Argentino de Antropología Social, Rosario.

Domenech, E. (2005). Migraciones contemporáneas y diversidad cultural en la Argentina. Universidad Nacional de Córdoba. Centro de Estudios Avanzados.

Filgueira, C. (2001). Estructura de oportunidades y vulnerabilidad social: aproximaciones conceptuales recientes. Ponencia presentada en: Seminario Internacional: Las Diferentes Expresiones de la Vulnerabilidad Social, Santiago de Chile.

Flier, P. G. (2018). Historias detrás de las memorias. Ensenada: Facultad de Humanidades y Ciencias de la Educación (UNLP).

Garatte, M.C. (2016). Entre la quinta, la escuela y la ciudad. Trayectorias laborales de jóvenes en el cinturón hortícola de La Plata (2003-2015). Tesis de grado, Universidad Nacional de La Plata, Facultad de Humanidades y Ciencias de la Educación, La Plata. En Memoria Académica. Recuperado de: http://www.memoria.fahce.unlp.edu.ar/te sis/te.1243/te.1243.pdf

García, M. (2011). Proceso de acumulación de capital en campesinos. El caso de los horticultores bolivianos de Buenos Aires (Argentina)", Cuadernos de Desarrollo Rural, Nro.66, $1^{\circ}$ semestre.

García, M. \& Le Gall, J. (2010). Reestructuraciones de las periferias hortícolas de Buenos Aires y modelos espaciales; Un archipiélago verde?. EchoGéo, no 11.

Gavazzo, N., Beheran, M. \& Novaro, G. (2014). La escolaridad como hito en las biografías de los hijos de bolivianos en Buenos Aires. Revista Interdisciplinar da Mobilidade Humana, 22(42), 189-212.

Guber, R. (2001). La etnografia: método, campo y reflexividad. Buenos Aires, Argentina: Norma.

Guerra, C. E. (2012). La educación secundaria en Argentina. Documento de trabajo. Universidad.

Hang, G.; Seibane, C.; Larrañaga, G.; Kebat, C.; Bravo, M.; Ferraris, G.; Otaño, M. \& Blanco, V. (2007). Identificación de Sistemas de Producción Hortícola en el Partido de La Plata, Provincia de Bs. As. Ponencia presentada en: $V$ Jornadas Interdisciplinarias de Estudios Agrarios y Agroindustriales. Facultad de Ciencias Económicas. UBA.

Lemmi, S. (2011). Las clases sociales en la horticultura platense. Mundo agrario, 12.

Lemmi, S. (2014). Vivir como peón, pensar como patrón”. Conflicto, organización política y conciencia de clase en el sector horticola del Gran La Plata (1953-2009). Tesis de Doctorado en Ciencias Sociales, Universidad Nacional de Quilmes, Quilmes.

Lemmi S. y García M. (2018). Cambios y continuidades en la estructura hortícola de La Plata (Buenos Aires) en los últimos 30 años. En: Banzato, Guillermo; Blanco, Graciela y Perrén, Joaquín (comp.), Expansión de la frontera productiva y estructura agraria argentina, siglos XIX-XXI. Prometeo-Asociación Argentina de Historia Económica. Buenos Aires.

Morzilli, M. (2019). Entre la quinta y la escuela, una bifurcación en la la "escalera boliviana". Trayectorias escolaresysocioproductivas de jóvenes de familias horticultoras bolivianas en el periurbano platense (2011-2017). Tesis Doctoral. Universidad Nacional de La Plata. Facultad de Humanidades y Ciencias de la Educación. 
Nobile, M. (2016). La escuela secundaria obligatoria en Argentina: desafíos pendientes para la integración de todos los jóvenes, Última Década, nro. 44.

Novaro, G. (2011).La Interculturalidad en Debate: experiencias formativas y procesos de identificación en niños indígenas $y$ migrantes. Buenos Aires: Editorial Biblos.

Novaro, G. (2016). Migración boliviana, discursos civilizatorios y experiencias educativas en Argentina, Nómadas $(\mathrm{Col}),(45)$.

Portelli, A. (2015). Historia oral, diálogo y géneros narrativos. Anuario de la Escuela de Historia, (26), 9-30.

Portelli, A. (2016). Historias orales: Narración, imaginación y diálogo. La Plata: Universidad Nacional de La Plata. Facultad de Humanidades y Ciencias de la Educación; Rosario: Prohistoria Ediciones.

Ringuelet, R.; Cacivio, R. \& Simonatto, S. (2006). Trama política, formas organizativas y desarrollo local en el mundo rural periurbano del Gran Buenos Aires. Revista Textual. Análisis del medio rural latinoamericano, 47.

Rockwell, E. (2009). La experiencia etnográfica. Historia y cultura en los procesos educativos. Buenos Aires: Paidós.

Rodríguez Valbuena, D. (2010). Territorio y territorialidad. Nueva categoría de análisis y desarrollo didáctico de la Geografía, Uni-pluriversidad.vol. 10, no 3.

Salva, L. R., \& Lago, G. (2012). Trayectorias escolares de niños y jóvenes hijos de trabajadores migrantes rurales en escuelas de los niveles primario y secundario de La Plata. Ponencia presentada en: VII Jornadas de Sociología de la Universidad Nacional de La Plata (La Plata, 2012), UNLP, La Plata.

Terigi, F. (2009). Las trayectorias escolares. Del problema individual al desafio de la politica educativa. Buenos Aires: Ministerio de Educación de la Nación.

Varesi, G. (2011). El giro progresista. Apuntes sobre alcances y límites del neodesarrollismo, Realidad económica, 264, 33-59.

Waisman, M. A. (2011). Superando dualismos: trayectorias socio-productivas en el abordaje de las transformaciones en la estructura social hortícola platense, Mundo agrario, 12.

\section{Notas}

1 El concepto de vulnerabilidad social está compuesto por dos planos: uno está referido al plano estructural/económico y se expresa en determinadas configuraciones individuales, o de los hogares, dada por una elevada propensión a una movilidad descendente. El segundo plano se refiere a sus consecuencias en la esfera subjetiva. La vulnerabilidad social genera sentimientos de indefensión, incertidumbre e inseguridad. Véase, al respecto el trabajo de Filgueira (2001).

2 Se eligió una Escuela Media Pública en la que un porcentaje relevante (casi la mitad de la matrícula) de sus alumnos/ as son migrantes bolivianos/as o hijos/as de migrantes bolivianos/as, y la misma se encuentra inserta en el periurbano hortícola platense.

3 Con respecto al marco teórico utilizado, el mismo ya fue implementando en otras investigaciones ya publicadas, empero, las categorías de análisis son aquí empleadas para alcanzar objetivos diferentes y relacionar dimensiones no abordadas en otros trabajos publicados.

4 Se debe señalar que algunas de las fuentes que se utilizaron en este trabajo también fueron utilizadas en otros trabajos ya publicados; sin embargo, el análisis que se realiza aquí de dichas fuentes difiere del análisis que se ha realizado en los trabajos ya publicados.

5 Como se ha señalado anteriormente, si bien el período histórico seleccionado para este trabajo hace referencia a los años 2011-2017 por ser la cohorte de alumnos/as seleccionados/as, empero en este apartado se remonta a la primera década del siglo XXI donde se dan los cambios políticos, económicos y sociales que repercuten en el tiempo vivenciado por la unidad de análisis. Sumado a esto se considera relevante historizar más a largo plazo el contexto histórico del periurbano hortícola platense, sin dejar de subrayar la incidencia inmediata del período elegido en los/as agentes.

6 Según Lemmi (2014), la escalera gringa fue posible por determinadas políticas públicas de acceso a la propiedad de la tierra.

7 Es necesario subrayar que las familias de los/as jóvenes seleccionados/as para el presente trabajo arribaron de Bolivia a Argentina entre la década del $90^{\prime}$ en algunos casos, y en otros casos, entre la primera y segunda década del siglo XXI.

8 Los/as migrantes bolivianos/as en los $70^{\prime}$ venían con la estrategia de transitar la escalera hortícola boliviana (Benencia, 1999). Sin embargo, el cambio de coyuntura político económica, sumado a la obligatoriedad del nivel incidieron que desplieguen nuevas estrategias vinculadas a la educación para alcanzar un movilidad social ascendente. 
9 Esta información puede confirmarse por los datos brindados por los/as entrevistados/as, como también por observación participante, al caminar por las calles en donde se sitúan las Quintas dedicadas a la producción de hortalizas en el periurbano platense.

10 Según fuentes periodísticas: Ámbito Financiero: https://www.ambito.com/productores-realizaron-un-nuevo-verdu razo-plaza-mayo-n3980355 Infobae: http://www.infobae.com/politica/2017/04/24/nuevo-verdurazo-en-la-plaza-de -mayo-regalaran-20-mil-kilos-de-alimentos/ Página 12: https://www.pagina12.com.ar/34243-verdurazo-permanente La Nación: https://www.lanacion.com.ar/economia/campo/verdurazo-pequenos-productores-plaza-de-mayo-nid201 6144

11 Según fuentes periodísticas: Infocampo: https://www.infocampo.com.ar/productores-realizaran-hoy-un-nuevo-verdu razo-en-plaza-de-mayo/ Infobae: https://www.infobae.com/politica/2017/04/24/nuevo-verdurazo-en-la-plaza-de-m ayo-regalaran-20-mil-kilos-de-alimentos/ Página 12: https://www.pagina12.com.ar/34243-verdurazo-permanente La Nación: https://www.lanacion.com.ar/economia/campo/verdurazo-pequenos-productores-plaza-de-mayo-nid20161 44

12 Esto pudo constatarse a través de las encuestas, las entrevistas, la observación participante y los registros estadísticos de la Escuela.

13 Esto pudo constatarse a través de las encuestas, las entrevistas, la observación participante y los registros estadísticos de la Escuela.

14 Las 21 entrevistas a jóvenes como a las 5 familias dieron cuenta de esto.

15 Algunos de los relatos utilizados aquí fueron publicados en otro trabajo pero para analizar relaciones con dimensiones diferentes.

16 Esto pudo constatarse a partir de las entrevistas a Alex, Andrea, Ayelen, Florencia, Ornella, Ronaldo, Giuliana, Yanet, Yanina, José P. y Nahuel, como también a través de los registros de la Escuela.

17 Esto pudo constatarse a partir de las entrevistas a Alex, Miriam, José, Ayelen y Sandro, como a su vez, en los registros de la Escuela.

18 En tanto que permiten unir en el análisis la historicidad de los procesos sociales, las constricciones estructurales y la agencia de los agentes (Waisman, 2011). 